\title{
MEMPEROLEH KESEMBUHAN DENGAN PARITTA (KAJIAN TERHADAP BOJJHANGA PARITTA SECARA ABHIDHAMMA)
}

\author{
Sugianto \\ STABN Sriwijaya \\ 5039lanto@gmail.com
}

\begin{abstract}
ABSTRAK
Kesehatan adalah harta yang paling berharga dalam kehidupan. Berbagai upaya dilakukan untuk menjaga kesehatan, di antaranya adalah dengan menjaga pola hidup sehat. Meskipun telah menjaga pola hidup sehat, sakit merupakan kondisi yang tidak terelakkan dalam suatu kehidupan. Penyakit adalah konsekuensi alami dari kelahiran. Untuk mengatasi penyakit, pada umumnya orang berobat. Buddhisme juga memiliki alternatif dalam mengatasi penyakit. Salah satu sumber dalam Buddhisme yang menjadi dasar untuk memperoleh kesembuhan adalah Bojjhanga Paritta. Kajian terhadap Bojjhanga Paritta diperlukan agar memberikan pemahaman yang mendalam. Salah satu cara mengkaji Bojjhanga Paritta adalah dengan menerapkan analisis secara Abhidhamma yang cenderung membahas kesadaran (citta), bentuk-bentuk batin (cetasika), dan materi (rupa). Hasil dari kajian ini diharapkan bermanfaat bagi masyarakat khususnya yang terlibat dalam bidang pendidikan agama dan keagamaan Buddha yang dikembangkan sebagai bahan edukasi Pendidikan Agama dan Keagamaan Buddha secara teoretis maupun praktis.
\end{abstract}

Kata Kunci: Kesembuhan, Bojjhanga Paritta, Abhidhamma

\section{PENDAHULUAN}

Kesehatan adalah harta yang paling berharga. Memiliki badan jasmani dan batin yang sehat memungkinkan seseorang melakukan berbagai aktivitas tanpa ada gangguan. Dengan memiliki kesehatan, memungkinkan melakukan berbagai kebaikan, mulai dari belajar dhamma sampai dengan praktik dhamma. Orang yang sehat mampu melaksanakan tugas dan tanggung jawab di lingkungan keluarga, masyarakat, dan profesi. Kesehatan mengondisikan batin dan jasmani menjadi tenang, tenteram, dan damai. Pikiran yang baik akan muncul dan berkembang, sedangkan pikiran yang tidak baik melemah dan berkurang. Timbulnya ketenangan, ketenteraman, dan kedamaian membuat hidup menjadi bahagia. Badan jasmani yang sehat memudahkan aktivitas tanpa ada gangguan atau kesakitan. Kesehatan juga membawa dampak positif lainnya yaitu biaya hidup lebih terkendali, kebutuhan relatif dapat diprediksi. Sebaliknya, bila sedang menderita sakit, sangat dimungkinkan pikiran buruk akan muncul dan berkembang seperti takut, 
khawatir, dan gelisah, aktivitas terganggu, serta akan ada pengeluaranpengeluaran ekstra untuk pengobatan.

Penyakit muncul karena faktor internal maupun eskternal. Faktor internal di antaranya adalah pola pikir, pola ucap, dan pola perbuatan yang membentuk pola hidup yang salah. Suka bergaul sampai di luar batas waktu normal, waktu tidur yang kurang, suka makan yang tidak sehat, suka minum minuman beralkohol bahkan mengonsumsi narkoba adalah contoh pola hidup yang salah. Faktor eksternal antara lain cuaca yang ekstrem, seperti terlalu panas atau terlalu dingin. Selain itu, karma atau perbuatan juga bisa menjadi sebab sakit.

Memiliki pola hidup sehat adalah upaya menjaga dan mendapatkan kesehatan. Pikiran terkendali, ucapan terkendali, perbuatan terkendali akan membentuk pola hidup yang sehat. Makan dengan gizi seimbang, tidur yang teratur dan cukup waktu, kerja atau belajar yang teratur merupakan bagian dari pola hidup sehat. Tinggal di lingkungan yang bersih dan sehat juga menjadi faktor yang mendukung kesehatan. Meskipun telah berupaya menjaga kesehatan, namun sakit tetap dapat terjadi. Menurut Buddhisme, selama masih ada kelahiran, akan muncul penyakit.

Pada umumnya masyarakat pergi berobat ke dokter bila menderita penyakit atau mengandalkan pengobatan herbal. Buddhisme juga memiliki cara untuk mengatasi penyakit. Ada beberapa kasus yang mendukung bahwa Buddhisme dianggap memberikan sumbangsih terhadap penyembuhan penyakit. Di antaranya dialami oleh umat Buddha dari Kelapa Gading, Jakarta yang menderita penyakit di otak sehingga membuat umat tersebut tidak sadarkan diri (koma), dokter pun memvonis peluang kesembuhan sangat kecil. Namun berkat pengertian benar yang dimiliki keluarga terhadap penyakit serta adanya pembacaan paritta terus-menerus dengan tulus dan ikhlas ternyata dapat membantu kesembuhan umat tersebut. Saat ini umat tersebut dinyatakan telah sembuh dari penyakit.

Kasus lain juga dialami umat Buddha dari Kelapa Gading yang menderita penyakit lupus, kemudian mengikuti meditasi kesehatan yang mengacu pada meditasi Buddhis. Pada akhirnya umat tersebut sembuh dari penyakit dan bisa melaksanakan aktivitas sehari-hari. Titik Puspa, seorang artis senior yang didiagnosis menderita kanker serviks sembuh karena dalam sela-sela pengobatan melakukan meditasi pernafasan. Dari beberapa kasus di atas, dapat diambil kesimpulan bahwa Buddhisme menjadi salah satu alternatif yang digunakan untuk memperoleh kesembuhan dengan mendengarkan paritta dan bermeditasi.

Untuk memahami lebih lanjut cara memperoleh kesembuhan menurut Buddhisme perlu adanya Buddhist studies atau kajian terhadap Buddhisme terhadap sumber atau ajaran Buddha yang dimaksud. Salah satu sumber Buddhisme yang dapat dikaji adalah Bojjhanga Paritta yang berisi tujuh faktor mencapai penerangan yaitu perhatian (sati), penyelidikan terhadap dhamma (dhammavicaya), semangat (viriya), kegiuran batin (piti), ketenangan 
(passaddhi), keteguhan batin (samadhi), dan keseimbangan batin (upekkha). Adapun strategi untuk mengkaji Bojjhanga Paritta dilakukan menurut Abhidhamma dengan cara menganalisis proses kesadaran yang muncul dan berkembang dalam proses kesembuhan. Inilah yang menjadi latar belakang penulisan artikel ini.

Rumusan masalah dalam artikel ini adalah bagaimanakah proses kesembuhan dengan menggunakan Bojjhanga Paritta menurut Abhidhamma? Tujuan dari penulisan ini adalah untuk menjelaskan proses penyembuhan dengan menggunakan Bojjhanga Paritta menurut Abhidhamma. Metode yang digunakan dalam melakukan kajian ini adalah dengan studi kepustakaan. Manfaat dari artikel ini adalah untuk memperkaya pengetahuan masyarakat terhadap Buddhist studies; sebagai referensi dalam melakukan terapan terhadap upaya mendapatkan kesembuhan dengan menggunakan metode Buddhisme.

Menurut Piyadasi, pikiran memiliki pengaruh yang besar terhadap kesehatan atau sebaliknya sakit. Pikiran mengondisikan seseorang sakit, dari pikiran juga dapat mengkondisikan kesembuhan. Dalam agama Buddha, ada hal menarik yang perlu dikaji yaitu hubungan paritta dengan kesembuhan. Paritta berasal dari bahasa Pali, atau dalam bahasa Sanskerta disebut paritrana, dan dalam bahasa Sinhala disebut pirit yang semuanya memiliki arti yang sama yaitu perlindungan (https://www.accesstoinsight.org/lib/authors/ piyadassi/protection.html).

Untuk mendapatkan berkah dari paritta dilakukan dengan cara membacakan atau mendengarnya. Khusus untuk mendapatkan berkah kesembuhan, ada satu kasus yang menarik dikaji dalam Bojjhanga Paritta yaitu Buddha dan murid beliau mendengarkan paritta. Menurut Piyadasi dengan mendengarkan paritta akan memunculkan kesejahteraan mental dan keyakinan terhadap ajaran Buddha yang ada dalam paritta. Kesejahteraan mental berupa kebahagiaan yang dapat mengobati penyakit. Pada saat kondisi sedang sakit, mendengarkan paritta lebih efektif daripada mengulang paritta, karena lebih mudah menjaga konsentrasi saat mendengarkan paritta. Hal ini seperti yang juga dinyatakan dalam Bojjhanga Paritta. Lebih lanjut, Piyadasi menjelaskan ada empat faktor yang mempengaruhi efektivitas paritta yaitu: kekuatan kebenaran yang ada dalam paritta, kekuatan sila atau moralitas yang mendengarkan paritta, kekuatan cinta kasih yang membaca paritta, dan kekuatan suara yang membacakan paritta (https://www.accesstoinsight.org/lib/authors/piyadassi/protection.html).

1. Bojjhanga Paritta

a. Tujuh Faktor Untuk Mencapai Penerangan

Faktor-faktor untuk memperoleh penerangan adalah perhatian (sati), penyelidikan dhamma (dhammavicaya), semangat (viriya), kegiuran batin (piti), ketenangan batin (passadhi), keteguhan batin (samadhi), dan keseimbangan batin (upekkha). Ketujuh faktor ini telah 
diajarkan dengan jelas oleh Sang Buddha. Bila dikembangkan dan dilatih menghasilkan pengetahuan luhur, kepadaman kilesa dan penerangan sempurna (Dhammaddhiro, 2013: 98).

b. Manfaat Bojjhanga Paritta

Berdasarkan isi dari Bojjhanga Paritta, tujuh faktor untuk mencapai penerangan sempurna dapat digunakan dalam penyembuhan penyakit. Ada tiga contoh yang disebutkan dalam Bojjhanga Paritta, yaitu Yang Ariya Moggalana, Yang Ariya Kassapa, dan Sang Buddha.

Pada suatu ketika Sang Buddha menjenguk Yang Ariya Moggalana dan Yang Ariya Kassapa yang sedang sakit. Kemudian Sang Buddha membabarkan tujuh faktor pencapaian penerangan. Yang Ariya Moggalana dan Yang Ariya Kassapa merasa bahagia mendengarkan pembabaran tujuh faktor pencapaian penerangan sempurna yang disampaikan oleh Sang Buddha dan sembuh dari sakit. Kemudian pada saat Sang Buddha menderita sakit, beliau meminta Yang Ariya Cunda Thera untuk mengulang tujuh faktor mencapai penerangan dengan saksama. Mendengar pengulangan tujuh faktor mencapai penerangan sempurna, Sang Buddha merasa bahagia dan sembuh dari penyakit. Inilah tiga contoh penggunaan Bojjhanga Paritta dalam upaya memperoleh kesembuhan. (Dhammaddhiro, 2013: 98)

\section{Abhidhamma}

Abhidhamma merupakan bagian dari Tipitaka yang berisi ajaran Buddha tentang filsafat, metafisika, dan ilmu jiwa Buddha Dhamma yang terdiri dari 42.000 kelompok Dhamma dan dibagi menjadi tujuh kitab yaitu: Dhammasangani, Vibhanga, Dhatukatha, Puggalapannati, Kathavatthu, Yamaka, dan Pathana. Ada banyak manfaat mempelajari Abhidhamma di antaranya adalah membawa kekhasiatan yaitu terbebas dari dukkha. Untuk memahami Abhidhamma membutuhkan kesabaran, ketekunan dan ketelitian, karena cara penyampaian yang ada dalam Abhidhamma tidak semudah yang ada dalam sutta. Oleh karena itu, Venerable Anuruddha-cariya Mahathera menyusun kitab Abhidhammatthasangaha yang berisi singkatan dari gabungan intisasri Abhidhamma Pitaka yang terdiri dari citta (kesadaran), cetasika (bentukbentuk batin), rupa (materi), dan nibbana (Kaharudin, 2005: 1-3).

Menurut Abhidhamma ada 89 atau 121 jenis kesadaran yang diketahui oleh pikiran, yaitu 54 jenis kesadaran yang berkelana di alam nafsu, 15 jenis kesadaran yang berkelana di alam rupa, 12 kesadaran yang berkelana di alam arupa, dan 8 atau 40 kesadaran yang objeknya di luar duniawi. Bentuk-bentuk pikiran ada 52 jenis, terdiri dari 13 bentukbentuk batin yang dapat bersekutu dengan kesadaran yang baik dan buruk, 14 bentuk-bentuk batin yang bersekutu dengan kesadaran yang 
tidak baik, dan 25 bentuk-bentuk batin yang bersekutu dengan kesadaran yang baik. Rupa (materi) adalah keadaan yang dapat bercerai atau berubah padam dengan kedinginan dan kepanasan terdiri dari 28 materi. Nibbana adalah kebahagiaan tertinggi yang terbebas dari kilesa.

Berdasarkan isi dari Bojjhanga Paritta, pada saat diperdengarkan isi dari tujuh faktor mencapai penerangan sempurna timbul kegembiraan sehingga sembuh dari sakit. Oleh karena itu, fokus pembahasan atau kajian Buddhis studi menurut Abhidhamma adalah perasaan. Perasaan dapat dibagi menjadi lima macam yaitu perasaan senang dari jasmani, perasaan senang dari batin, perasaan derita dari jasmani, perasaan tidak senang dari batin, dan perasaan seimbang yaitu bukan senang pun bukan derita.

\section{PEMBAHASAN}

Kesehatan merupakan hal yang sangat berharga bagi semua orang. Pada umumnya, semua orang berharap dapat senantiasa hidup sehat. Memiliki badan jasmani dan batin yang sehat, terbebas dari gangguan penyakit baik penyakit fisik ataupun penyakit mental. Menderita penyakit dapat mengganggu aktivitas sehari-hari, bahkan dalam kasus yang berat dapat mengganggu keuangan. Tabungan akan berkurang atau habis, bahkan harta benda lainnya pun dapat dijual untuk membayar biaya penyembuhan. Dengan menderita penyakit, akan ada pengeluaran-pengeluaran ekstra yang harus dibayarkan untuk mengobati penyakit.

Meskipun saat ini ada jasa asuransi yang menyediakan layanan pembayaran pengobatan, namun hal itu tidak membuat orang senang menderita penyakit. Berbagai upaya dilakukan untuk menjaga kesehatan, di antaranya pola hidup yang sehat, makan dengan kandungan gizi yang seimbang, istirahat yang cukup, dan juga melakukan kegiatan refreshing seperti berlibur, atau ikut kegiatan meditasi agar pikiran bebas dari stres akibat banyak hal yang dipikirkan. Sehubungan dengan upaya mendapatkan kesehatan, ada hal yang menarik yang ada dalam Buddhisme. Sebagai paham atau keyakinan yang mengacu pada ajaran Buddha, Buddhisme menawarkan kesehatan dengan cara yang unik, yaitu dengan mendengarkan paritta.

Paritta atau perlindungan dalam Buddhisme diyakini memberi efek kesembuhan. Oleh karena itu, hubungan antara paritta dengan kesembuhan merupakan salah satu hal yang menarik untuk dikaji. Apalagi di zaman seperti sekarang ini, di saat ditemukan berbagai macam jenis penyakit yang membuat masyarakat menjadi resah dan gelisah. Paritta dapat menjadi alternatif bagi masyarakat yang ingin atau berharap mendapatkan kesembuhan. Salah satu paritta yang diyakini memberi dampak kesembuhan adalah Bojjhanga Paritta.

Bojjhanga paritta berisi ajaran Buddha tentang tujuh faktor mencapai penerangan sempurna yaitu perhatian (sati), penyelidikan dhamma 
(dhammavicaya), semangat (viriya), kegiuran batin (piti), ketenangan batin (passadhi), keteguhan batin (samadhi), dan keseimbangan batin (upekkha). Untuk mendapatkan kesembuhan dengan paritta ini, ketujuh faktor penerangan sempurna ini didengarkan dengan penuh perhatian sehingga muncul perasaan gembira yang secara otomatis membuat penyakit yang diderita menjadi hilang.

1. Perhatian (sati)

Ada empat hal yang menjadi objek perhatian yaitu perhatian kepada badan jasmani, perhatian kepada perasaan, perhatian kepada pikiran, dan perhatian kepada objek-objek pikiran. Badan jasmani merupakan perpaduan dari empat unsur yaitu unsur padat, air, panas, dan udara. Pada saat tertentu, badan jasmani mengalami sakit. Oleh karena itu, perhatian kepada bagian yang sakit dikembangkan. Salah satu cara untuk melatih perhatian badan jasmani adalah dengan memperhatikan proses nafas masuk dan nafas keluar. Menyadari ketika sedang mengirup nafas ataupun sedang menghembuskan nafas. Perhatian terhadap perasaan dapat dilatih dengan cara senantiasa menyadari perasaan yang sedang muncul. Ketika muncul perasaan bahagia, disadari sebagai perasaan bahagia. Ketika muncul perasaan tidak bahagia, disadari sebagai perasaan tidak bahagia. Ketika muncul perasaan netral, disadari sebagai perasaan yang netral. Perasaan dapat muncul karena adanya kontak antara indera dengan objek indera, seperti ketika mata melihat pemandangan akan muncul perasaan senang, tidak senang, ataupun netral. Perasaan muncul sebagai akibat dari adanya kontak antara indera dengan objek indera. Perhatian terhadap pikiran dapat dilatih salah satunya dengan menyadari faktor-faktor yang menjadi rintangan batin yaitu nafsu indera, kebencian, kelambanan, kegelisahan dan kekhawatiran, dan keragu-raguan. Menyadari saat munculnya faktorfaktor rintangan batin itu muncul, dan saat tidak muncul. Perhatian terhadap objek-objek pikiran dapat dilatih dan dikembangan dengan menyadari faktor-faktor untuk mencapai pandangan benar, atau empat kebenaran mulia.

2. Penyelidikan dhamma (dhammavicaya)

Penyelidian dhamma dilakukan dengan melakukan analisis yang tajam terhadap segala sesuatu menurut perspektif Buddha Dhamma. Dhamma yang menjadi ajaran Buddha apabila dikelompokkan jumlahnya sangat banyak yaitu 84.000 kelompok dhamma. Pada saat kondisi sakit, penyelidikan terhadap dhamma dapat dilakukan untuk mengingatkan kembali akan ajaran Buddha serta membangkitkan keyakinan serta bentuk-bentuk batin positif lainnya. Misalnya, saat sakit melakukan penyelidikan dhamma terkait manusia yang disusun dari panca khanda, yaitu perpaduan antara badan jasmani, perasaan, pencerapan, bentukbentuk batin, dan kesadaran. Bahwa panca khanda atau lima kelompok kehidupan merupakan kondisi yang masih mengalami ketidakkekalan, 
tidak memuaskan, dan tanpa inti atau aku yang kekal. Oleh karena itu, panca khanda yang secara umum disebut batin dan jasmani masih mengalami kondisi yang tidak menyenangkan yang dapat menyebabkan rasa sakit.

Dengan melakukan penyelidikan dhamma terhadap panca khanda, pada saat sakit batin dapat menerima kondisi tersebut dengan benar. Sakit merupakan kondisi alamiah yang dialami oleh semua makhluk yang dilahirkan. Tidak menyalahkan orang lain atau faktor lain terhadap penyakit yang sedang diderita. Namun ada usaha untuk mengobati penyakit secara medis maupun spiritual dengan mengembangkan tujuh faktor penerangan sempurna.

3. Semangat (viriya)

Semangat merupakan bagian dari unsur Jalan Tengah, yaitu usaha benar. Ada empat cara mengembangkan usaha yang benar, yaitu: usaha untuk melemahkan dan membuang pikiran-pikiran yang tidak baik yang telah muncul, mencegah munculnya pikiran yang tidak baik, memunculkan pikiran-pikiran yang baik, dan mengembangkan pikiran baik yang telah ada. Saat kondisi fisik atau batin sakit, pada umumnya muncul pikiran yang tidak baik. Oleh karena itu, perlu ada semangat untuk memunculkan pikiran-pikiran yang positif. Setelah muncul pikiran positif, kemudian dipertahankan dan dikembangkan.

4. Kegiuran (piti)

Salah satu tahapan dalam upaya mencapai batin yang terkonsentrasi adalah mengalami piti atau kegiuran batin. Sebuah sensasi kebahagiaan yang luar biasa dirasakan oleh badan jasmani dan batin. Kegiuran muncul ketika batin telah mengarah pada konsentrasi terhadap salah satu objek, misalnya pernafasan. Salah satu contoh bentuk kegiuran adalah muncul perasaan yang sangat bahagia dengan diiringi bulu kuduk merinding, sensasi lainya adalah badan terasa menjadi sangat ringan. Pengalaman telah merasakan suatu kegiuran menjadi daya tarik untuk mengulangi sensasi tersebut. Ketika kegiuran muncul akan menimbulkan kebahagiaan yang luar biasa secara badan jasmani maupun batin.

5. Ketenangan (passadhi)

Ada dua macam ketenangan yaitu ketenangan jasmani dan ketenangan batin. Ketenangan merupakan kondisi di saat pikiran terkendali, tidak memikirkan hal-hal yang membuat pikiran menjadi gelisah atau khawatir. Kegelisahan muncul manakala memikirkan hal-hal baik yang seharusnya dilakukan tapi pada kenyataannya belum dilakukan. Kekhawatiran muncul manakala memikirkan hal-hal negatif yang telah dilakukan, khawatir orang lain akan mengetahui, khawatir dengan hukuman atau sanksi yang akan diterima. Bila pikiran terbebas dari kegelisahan dan kekhawatiran, maka muncul ketenangan.

6. Keteguhan atau konsentrasi (samadhi) 
Konsentrasi adalah kemampuan batin dalam memfokuskan pada satu objek tanpa terganggu dengan objek lain. Konsentrasi dapat dikembangkan manakala batin sudah tenang. Ada berbagai gangguan dalam usaha mencapai tingkatan konsentrasi, antara lain: munculnya hawa nafsu, timbul keinginan jahat, ada kemalasan dan kelambanan, timbul kegelisahan dan kekhawatiran, serta adanya keragu-raguan pada Tiratana. Untuk mencapai konsentrasi, maka rintangan-rintangan tersebut harus diatasi terlebih dahulu. Berusaha agar hawa nafsu tidak muncul, niat jahat tidak muncul, semangat dimunculkan, fokus pada situasi saat ini, dan menumbuhkan keyakinan pada Tiratana.

7. Keseimbangan Batin (upekkha)

Keseimbangan batin merupakan kondisi batin yang netral, tidak terpengaruh dengan kondisi-kondisi baik yang menyenangkan maupun tidak menyenangkan. Ada delapan kondisi duniawi yang dapat mengguncang batin seseorang, yaitu untung atau rugi, memiliki kedudukan atau tidak punya kedudukan, dipuji atau dicela, serta bahagia atau menderita. Pikiran yang tidak seimbang cenderung menyenangi halhal yang membahagiakan dan menolak hal-hal yang tidak membahagiakan. Apabila keinginan tersebut tidak terwujud maka muncul kekecewaan. Batin yang tenang seimbang tidak terpengaruh dengan kondisi-kondisi di sekitar baik yang menyenangkan maupun tidak menyenangkan. Seseorang yang mengembangkan upekkha memiliki batin yang tenang dan terkonsentrasi.

Buddha dan para arahat adalah orang-orang yang telah merealisasikan penerangan sempurna. Berdasarkan pencapaian tersebut, tujuh faktor penerangan sempurna telah sepenuhnya ditembus. Oleh karena itu, ketika ada pengulangan terhadap tujuh faktor penerangan sempurna, para arahat dapat segera mengarahkan perhatian yang benar, melakukan penyelidikan dhamma, timbul semangat, memunculkan kegiuran, muncul ketenangan, batin terkonsentrasi, dan mencapai ketenangan batin. Penjelasan tentang tujuh faktor penerangan sempurna yang disampaikan oleh orang lain menjadi stimulus yang direspons dengan cepat oleh arahat yaitu munculnya perasaan gembira yang dengan serta merta membuat penyakit yang diderita menjadi sembuh.

Perasaan gembira yang muncul saat mendengarkan tujuh faktor penerangan sempurna yang dialami oleh Yang Ariya Moggalana, Yang Ariya Kassapa, dan Sang Buddha merupakan perasaan gembira yang berbeda dengan perasaan yang dirasakan oleh manusia biasa. Perasaan gembira batin atau jasmani yang dialami oleh manusia biasa dapat bersekutu dengan kesadaran yang tidak baik dan kesadaran yang baik. Perasaan gembira yang bersekutu dengan kesadaran yang tidak baik dikarenakan adanya keserakahan atau ketertarikan pada objek yang menyenangkan. Perasaan gembira yang bersekutu dengan kesadaran yang 
baik dikarenakan adanya ketertarikan pada objek yang menyenangkan karena disertai dengan pengetahuan atau kebijaksanaan.

Perasaan gembira yang dirasakan oleh Buddha ataupun arahat termasuk dalam kelompok kesadaran mahakiriya yang bukan masuk kategori kesadaran bukan kusala (baik), kesadaran bukan akusala (tidak baik), dan bukan kesadaran vipaka (hasil). Mahakiriya adalah kesadaran yang bertugas menerima objek dari enam landasan indera (mata, telinga, hidung, lidah, tubuh, dan pikiran) yang tidak menghasilkan suatu akibat. Pada kasus yang terjadi dalam Bojjhanga Paritta, perasaan gembira muncul karena mendengar pembabaran tujuh faktor penerangan sempurna serta merenungkan kembali faktor-faktor untuk mencapai penerangan.

\section{SIMPULAN}

Bojjhanga Paritta merupakan salah satu paritta yang dibacakan untuk memperoleh keberkahan yang pada khususnya adalah kesehatan. Ada tujuh faktor mencapai penerangan yang menjadi inti pokok dari isi Bojjhanga Paritta, yaitu: perhatian (sati), penyelidikan dhamma (dhammavicaya), semangat (viriya), kegiuran batin (piti), ketenangan batin (passadhi), keteguhan batin (samadhi), dan keseimbangan batin (upekkha). Sesuai isi dari Bojjhanga Paritta, orang yang mendengarkan isi dari tujuh faktor mencapai penerangan merasa bahagia dan penyakitnya hilang. Perasaan bahagia yang dialami oleh para arahat dengan manusia yang belum mencapai kesucian memiliki perbedaan terutama pada jenis pikiran yang muncul dan berkembang. Perasaan bahagia yang dimiliki arahat atau makhluk yang sepenuhnya suci berada pada jenis mahakiriya-citta yang tidak menimbulkan akibat. Bagi manusia yang belum mencapai kesucian, perasaan bahagia muncul pada jenis kesadaran yang masih terkait dengan hawa nafsu. Oleh karena itu, proses kesembuhan dengan menggunakan Bojjhanga Paritta antara arahat dengan manusia yang belum mencapai kesucian berbeda. Bila arahat bisa langsung sembuh, maka manusia yang belum suci butuh proses yang lebih lama.

\section{DAFTAR REFERENSI}

Dhammadhiro. 2005. Paritta Suci. Jakarta: Sangha Theravada Indonesia

Kaharudin, Pandit Jinaratana. 2005. Abhidhammatthasangaha. Jakarta: Yanwreko Wahana Karya.

Nanaponika. Abhidhamma Studies: Researches in Buddhist Psychology. Kandy: Buddhist Publication Society

NandamÜÜ̈hivaÊิ sa. 2005. Fundamental Abhidhamma Part I. Centre for Buddhist Studies (CBS), Mahübubodhayon Monastery, Sagaing Hills, Sagaing, Myanmar. 
NandamÜÜ̈hivaỄ sa. 2005. Fundamental Abhidhamma Part I. Centre for Buddhist Studies (CBS), Mahüsubodhayon Monastery, Sagaing Hills, Sagaing, Myanmar.

Piyadasi. Tanpa Tahun. The Book of Protection. Sumber online: https://www.accesstoinsight.org/lib/authors/piyadassi/protection.html (diakses pada tanggal 16 Oktober 2017).

Piyadasi. Tanpa Tahun. Tujuh Faktor Penerangan Sempurna. Sumber online: https://samaggi-phala.or.id/naskah-dhamma/tujuh-faktor-penerangansempurna/ (diakses pada tanggal 16 Oktober 2017).

Sikkhühanda. 2011. Dasar-Dasar Abhidhamma: Citta dan Cetasika (Kesadaran dan Faktor Mental). Hmawbi : Chanmyay Yeiktha Meditation Center. 